\title{
Analysis of Copper in the In-Tank Precipitation Process Caustic Samples
}

by

L. L. Tovo

Westinghouse Savannah River Company

Savannah River Site

Aiken, South Carolina 29808

W. T. Boyce

MASTER

DASTRIBUTION OF THI DECLRDENT IS UNLMITED

This paper was prepared in connection with work done under the above contract number with the U. S. Department of Energy. By acceptance of this paper, the publisher and/or recipient acknowledges the U. S. Government's right to retain a nonexclusive, royalty-free license in and to any copyright covering this paper, along with the right to reproduce and to authorize others to reproduce all or part of the copyrighted paper. 


\section{DISCLAIMER}

This report was prepared as an account of work sponsored by an agency of the United States Government. Neither the United States Government nor any agency thereof, nor any of their employees, makes any warranty, express or implied, or assumes any legal liability or responsibility for the accuracy, completeness, or usefulness of any information, apparatus, product, or process disclosed, or represents that its use would not infringe privately owned rights. Reference herein to any specific commercial product, process, or service by trade name, trademark, manufacturer, or otherwise does not necessarily constitute or imply its endorsement, recommendation, or favoring by the United States Government or any agency thereof. The views and opinions of authors expressed herein do not necessarily state or reflect those of the United States Government or any agency thereof.

This report has been reproduced directly from the best available copy.

Available to DOE and DOE contractors from the Office of Scientific and Technical Information, P. O. Box 62, Oak Ridge, TN 37831; prices available from (423) 576-8401.

Available to the public from the National Technical Information Service, U. S. Department of Commerce, 5285 Port Royal Road, Springfield, VA 22161. 


\section{DISCLAIMER}

Portions of this document may be illegible electronic image products. Images are produced from the best available original document. 


\section{Savannah River Technology Center}

WSRC-TR-96-0400

Keywords:

ICPES

ICPMS

Copper

ITP

\section{ANALYSIS OF COPPER IN THE IN-TANK PRECIPITATION PROCESS CAUSTIC SAMPLES (U)}

L. L. Tovo

W. T. Boyce

December 12, 1996

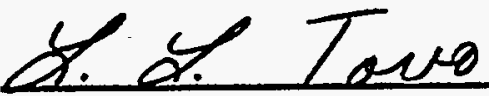

L. L. Tovo

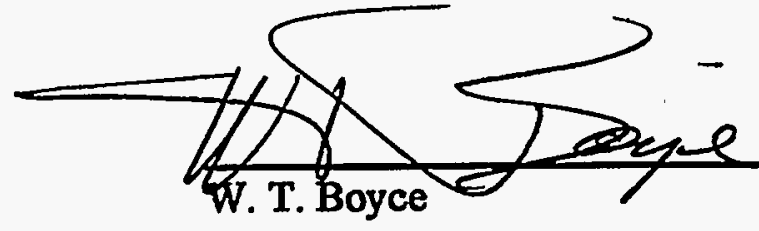




\section{$\underline{\text { Summary }}$}

Inductively Coupled Plasma Emission Spectroscopy (ICPES) and Inductively Coupled Plasma Mass Spectrometry (ICPMS) procedures for measuring $\mathrm{Cu}$ in In-Tank Precipitation (ITP) caustic samples have been tested and implemented in the Analytical Development Section at the Savannah River Technology Center. Prior to introduction to the instruments, the samples must be acidified to a $\mathrm{pH} \leq 2$ and diluted so that the total dissolved solids is less than $1 \%$ for ICPES and less than $0.1 \%$ for ICPMS. For the sample matrix listed in table 1 , using $2 \%$ nitric acid as the diluent (routine practice) is not sufficient to acidify the sample for ICPES analysis and $\mathrm{Cu}$ precipitation is the probable cause of the inconsistent spike recoveries previously observed. By increasing to 5\% nitric acid, an ICPES method detection limit (mdl) of $0.3 \mathrm{mg} /$ liter and an accuracy of $10 \%$ at $1 \mathrm{mg} /$ liter $\mathrm{Cu}$ can be achieved. In the ICPMS method, the sample matrix listed in table 1 gives a mdl of $0.4 \mathrm{mg} /$ liter and $\mathrm{Cu}$ can be measured at $1 \mathrm{mg} /$ liter with an accuracy of $30 \%$.

\section{Recommendations}

- Samples should be acidified to a $\mathrm{pH} \leq 2$ and diluted so that the total dissolved solids is less than $1 \%$ for ICPES and less than $0.1 \%$ for ICPMS. For the sample matrix listed in table 1, acidification and total dissolved solids reduction can be accomplished by a $10 \mathrm{X}$ dilution with $5 \%$ nitric acid for ICPES and a $100 \mathrm{X}$ dilution with $1 \%$ nitric acid for ICPMS.

- A spiked sample should be analyzed with each sample.

- A mdl for each batch of samples should be established using a synthetic salt blank diluted to the same concentration as estimated for the samples.

\section{Introduction}

The measurement of $\mathrm{Cu}$ in ITP samples by ICPES and ICPMS is difficult due to the complexity of the ITP sample matrix (See Table 1). Recoveries from samples, spiked with $1 \mathrm{mg} / \mathrm{liter} \mathrm{Cu}$ and analyzed using the ADS routine ICP procedures, have varied from $3.5 \%$ to $70 \%$. The customer requires a measurement method that can reliably measure $\mathrm{Cu}$ to at least $0.5 \mathrm{mg} / \mathrm{liter}$ and be accurate to within $30 \%$ at a concentration of $1.5 \mathrm{mg} / \mathrm{liter}$.

Both ICPES and ICPMS require that the high salt sample be diluted to reduce the dissolved solids concentration and matrix effects (i.e. background noise and molecular ion interferences). Generally, copper is easily detected by ICP techniques. The element has two isotopes, ${ }^{63} \mathrm{Cu}$ and ${ }^{65} \mathrm{Cu}$, with natural abundance of $\sim 69 \%$ and $\sim 31 \%$ respectively. 
The instrument background spectrum, under ideal conditions, shows only a little noise at both masses. Defining instrument detection limit as 10 standard deviations of the blank response, at masses 63 and 65, ICPMS can measure $\mathrm{Cu}$ at $0.1 \mathrm{ug} /$ liter. Under ideal conditions, the ICPES Cu instrument detection limit is $0.005 \mathrm{mg} /$ iter at $324.754 \mathrm{~nm}$.

\section{Experimental}

An ITP Tank 48 Batch 1 salt solution was obtained from IWT for testing the ICPES and ICPMS measurement methods. The composition of the Tank 48 solution is given in Table 1.

Table 1. Composition of Tank 48 Solution

\begin{tabular}{ll}
\hline Component & Concentration \\
\hline Total Na & $3.5 \mathrm{M}$ \\
Free OH & $1.7 \mathrm{M}$ \\
Nitrate & $0.4 \mathrm{M}$ \\
Nitrite & $0.5 \mathrm{M}$ \\
Carbonate & $0.2 \mathrm{M}$ \\
Aluminate & $0.1 \mathrm{M}$ \\
Chloride & $0.013 \mathrm{M}$ \\
Phosphate & $0.008 \mathrm{M}$ \\
Sulfate & $0.003 \mathrm{M}$ \\
Oxalate & $0.005 \mathrm{M}$ \\
Zn & $7 \mathrm{mg} /$ liter \\
Mo & $10 \mathrm{mg} /$ liter \\
Sn & $3 \mathrm{mg} /$ liter \\
Cr & $55 \mathrm{mg} /$ liter \\
& \\
\hline
\end{tabular}

\section{ICPES}

Calibration solutions were made by the appropriate volumetric dilution of a $1000 \mathrm{mg} /$ iter $\mathrm{Cu}$ in $2 \%$ nitric acid standard from High Purity, Inc.. Dilutions were made using $5 \%$ nitric acid prepared using Seastar 16 molar nitric acid and 18 megaohm Millipore deionized water. Calibration standard concentrations used were $0.0,1.0$ and $10.0 \mathrm{mg} / \mathrm{liter}$.

Spikes were prepared by adding the appropriate volume of a $10 \mathrm{mg} / \mathrm{liter} \mathrm{Cu}$ standard (prepared from the $1000 \mathrm{mg} /$ liter $\mathrm{Cu}$ standard from High Purity) to the Tank 48 salt solution or to a $10 \mathrm{X}$ dilution of an ITP sample.

ICPES measurements were made using a Leeman PS1000 for non-radioactive samples and an ARL 3580 for radioactive samples. An ICPES measurement consists of three thirty 
second integrations at $324.754 \mathrm{~nm}$ for each of the standards and samples. A sample uptake time of 75 seconds was used and a 4 minute rinse between samples was required.

Prior to measurement by ICPES, the solution needs to be acidified to a $\mathrm{pH} \leq 2$. Using $2 \%$ nitric acid as the diluent (routine practice) is not sufficient to acidify the sample unless a 100X dilution is made. However, a method detection limit (mdl) of $0.3 \mathrm{mg} /$ liter (5 sigma) was calculated from 10 determinations of the ITP Tank 48 salt solution. Whether the source of this increased mdl, as compared to an mdl from an acidic non-salt solution, is the result of matrix effects or $\mathrm{Cu}$ contamination of the salt solution is not known at this time. This mdl does preclude the use of a $100 \mathrm{X}$ dilution. Therefore, a $10 \mathrm{X}$ dilution is the most dilute solution that can be used and $5 \%$ nitric acid is required as the diluent to ensure that the solution is acidified to a $\mathrm{pH} \leq 2$.

The Tank 48 matrix solution was spiked with $1 \mathrm{mg} /$ liter $\mathrm{Cu}$ standard. From this spiked solution, five 1 milliliter aliquots were diluted with 9 milliliters of $5 \%$ nitric acid. These 5 dilutions were analyzed at least twice to demonstrate reproducibility. The results are summarized in Table 2.

Table 2. ICPES Results from a $1.0 \mathrm{mg} /$ liter Cu Spiked ITP Salt Matrix.

\begin{tabular}{|c|c|c|c|c|c|}
\hline & $\begin{array}{l}\text { Dilution } 1 \\
\mathrm{Cu} \text { (mg/iter) }\end{array}$ & $\begin{array}{l}\text { Dilution } 2 \\
\mathrm{Cu} \text { (mg/iter) }\end{array}$ & $\begin{array}{l}\text { Dilution } 3 \\
\mathrm{Cu} \text { (mg/liter) }\end{array}$ & $\begin{array}{l}\text { Dilution 4 } \\
\text { Cu (mg/liter) } \\
0.97\end{array}$ & $\begin{array}{l}\text { Dilution } 5 \\
\mathrm{Cu} \text { (mg/liter) } \\
0.94\end{array}$ \\
\hline & 1.02 & 0.98 & 0.96 & & \\
\hline & 0.94 & 0.97 & 1.04 & 1.01 & 0.99 \\
\hline & 0.91 & 1.07 & -- & - & 0.99 \\
\hline & 0.90 & 0.99 & - & - & 1.00 \\
\hline & 1.00 & - & - & - & - \\
\hline Average & 0.95 & 1.00 & 1.00 & 0.99 & 0.98 \\
\hline Std. Dev. & 0.05 & 0.05 & 0.05 & 0.03 & 0.03 \\
\hline$\%$ RSD & 5 & 5 & 5 & 3 & 3. \\
\hline
\end{tabular}

All spike recoveries are between $90 \%$ and $110 \%$. The data in Table 2 also shows the excellent reproducibility of the sample dilutions and instrument measurements.

Next, actual ITP research samples were analyzed and the results are summarized in Table 3. Samples 30007776,30007777 and 300061327 were diluted $10 \mathrm{X}$ with $5 \%$ nitric acid. The ten remaining samples ${ }^{1}$ had been acidified to a $\mathrm{pH}=2$ by the customer prior to submission for analysis. Therefore, these samples were diluted with $2 \%$ nitric according to routine procedures. All spike recoveries are within $20 \%$. 
Table 3. ICPES Results of ITP Samples.

\begin{tabular}{lllll}
\hline LIMS \# & $\begin{array}{l}\text { Sample Unspiked } \\
\text { Cu (mg/liter) }\end{array}$ & $\begin{array}{l}\text { Spike Conc. } \\
\text { (mg/liter) }\end{array}$ & $\begin{array}{l}\text { Sample + Spike } \\
\text { Cu (mg/liter) }\end{array}$ & \% Recovery \\
\hline 30007776 & -0.297 & 1.0 & 0.9517 & 95 \\
30007777 & 0.679 & - & - & - \\
300061327 & 0.023 & 1.0 & 1.005 & 98 \\
300061327 & 0.023 & 0.2 & 0.221 & 99 \\
300075187 & 0.0568 & 0.2 & 0.2380 & 91 \\
300075188 & 0.3613 & 0.2 & 0.5377 & 88 \\
300076152 & 0.0511 & 0.05 & 0.0918 & 81 \\
300076153 & 0.2677 & 0.2 & 0.4410 & 87 \\
300079985 & 0.0637 & 0.05 & 0.1103 & 93 \\
300079988 & 0.2516 & 0.05 & 0.2959 & 89 \\
300079989 & 0.0341 & 0.2 & 0.2222 & 94 \\
300079990 & 0.0084 & 0.05 & 0.0562 & 96 \\
300080384 & 0.1706 & 0.2 & 0.3651 & 97 \\
300080385 & 0.0743 & 0.05 & 0.1158 & 83 \\
\hline
\end{tabular}

** Not corrected for $10 \mathrm{X}$ dilution.

\section{ICPMS}

When $\mathrm{Cu}$ is present in a high sodium matrix ( $9.2 \mathrm{mg} / \mathrm{liter}$ or greater), the molecular ion, $\mathrm{ArNa}$, begins to appear at mass 63 . The $\mathrm{Cu}$ isotope ratio increases dramatically with increasing $\mathrm{Na}$ ion concentration, making the mass 63 response for $\mathrm{Cu}$ unusable. At the same time, a peak begins to appear at mass 62 . Although it is not mentioned in the library of molecular ion interferences included in the instrument software, mass 62 corresponds to $\mathrm{Na}_{2} \mathrm{O}$. The relative intensities of both the mass 62 and mass 63 responses are equal and both increase at the same rate as the $\mathrm{Na}$ ion concentration increases.

The Cu isotope at mass 65 is not significantly bothered by a molecular ion interference with a $100 X$ dilution of the Tank 48 solution. The detection limit, as calculated from the average response of the Tank 48 salt solution, is 4 ug/liter as compared to the detection limit of 0.1 ug/liter at mass 63 calculated from the standard blank (no salt matrix). As with ICPES, whether the salt solution. response is the result of matrix effects or from $\mathrm{Cu}$ contamination of the salt solution has not been determined at this time.

Another effect of the high salt concentration is the suppression of the instrument response. This is demonstrated by monitoring the response of the $\mathbf{5 0}$ ug/iter Indium 
internal standard at mass 115 . In $920 \mathrm{mg} /$ liter salt solutions, the response suppression is about $25 \%$ of its value in the non salt containing standards.

Five aliquots of the unspiked and $\mathrm{Cu}$ spiked salt solution were prepared by adding 0.1 milliliter of the tank 48 salt solution plus 0.05 milliliter of a $10 \mathrm{ug} / \mathrm{liter} \mathrm{In} / \mathrm{Sc} / \mathrm{Bi}$ internal standard solution to 9.85 milliliters of a dilute nitric acid solution. The internal standard concentration in the dilution was $50 \mathrm{ug} / \mathrm{liter}$. The nitric acid diluent was prepared by adding 25 milliliters of $16 \mathrm{M}$ ultra high purity nitric acid to 4 liters of $18 \mathrm{megaohm}$ Millipore deionized water. . In all 10 sample preparations, the solution $\mathrm{pH} \leq 1$.

Mass spectrometer concentration calibration solutions were prepared by appropriate volumetric dilution of a $10 \mathrm{ug} / \mathrm{liter}$ High Purity, Inc. mixed element concentration standard (ICPMS-CS) that contained $\mathrm{Cu}$. The calibration concentrations were blank, 0.1 ug/iter, 0.5 ug/liter, 1 ug/iter, 5 ug/iter, 10 ug/liter, 50 ug/iter, and 100 ug/iter. Each concentration standard and blank also contained 50 ug/iter of the $\mathrm{Sc} / \mathrm{In} / \mathrm{Bi}$ internal standard.

The Fisons PQ1 ICPMS was used for analysis. Four one minute scans from mass 43 to mass 249 were made on each sample and standard. A ninety second sample/standard uptake was selected. At the end of the four data acquisitions, the sample delivery system was washed for 90 seconds. A one minute wash is necessary to return the mass 65 response to background levels.

The standard/sample run sequence had the standards in increasing concentration order followed by alternating the unspiked and spiked samples. After the last spiked sample, a 10. minute wash was required to eliminate $99 \%$ of the ArNa response at mass 62 . Then the standards were run again.

Table 4. ICPMS Results from a 10 ug/liter Cu Spiked ITP Salt Matrix

\begin{tabular}{|c|c|c|c|c|}
\hline Dilution \# & $\begin{array}{l}\text { Sample Unspiked } \\
\mathrm{Cu}(\mu \mathrm{g} / \mathrm{liter})\end{array}$ & $\begin{array}{l}\text { Sample + Spike } \\
\text { Cu (ug/liter) }\end{array}$ & $\begin{array}{l}\because \text { Cu Recovery } \\
\therefore \text { ( } \mathrm{gg} / \mathrm{hiter})\end{array}$ & \% Recovery \\
\hline 1 & 2.9 & 15.8 & 12.9 & 129 \\
\hline 2 & 4.1 & 15.4 & 11.3 & 113 \\
\hline 3 & 3.5 & 15.2 & 11.7 & 117 \\
\hline 4 & 4.1 & 16.7 & 12.6 & 126 \\
\hline 5 & 3.6 & 16.2 & $\because 12.6$ & 126 \\
\hline Average & 3.6 & 15.9 & 12.2 & 122 \\
\hline Std. Dev. & 0.5 & 0.6 & 0.7 & 6.6 \\
\hline$\%$ RSD & 13.2 & 3.7 & 5.4 & 5.4 \\
\hline
\end{tabular}




\section{Conclusions}

Copper can be measured in ITP caustic solutions by ICPES and ICPMS. Prior to introduction to the instruments, the samples must be acidified to a $\mathrm{pH} \leq 2$ and diluted so that the total dissolved solids is less than $1.0 \%$ for ICPES and less than $0.1 \%$ for ICPMS. Spiked samples should be run as verification that there is no loss of $\mathrm{Cu}$. A different sample matrix from the one listed in table 1 will require the determination of a new mdl.

\section{References}

1. M. J. Barnes, T. B. Edwards, Copper Catalyzed Sodium Tetraphenylboron Decomposition Kinetic Studies (U), WSRC-TR-96-0351, Savannah River Site, Aiken, SC, (1996). 
OSR3-4A-W (Rev1-89)

WESTINGHOUSE SAVANNAH RIVER COMPANY INTER-OFFICE MEMORANDUM

December 12, 1996

WSRC-TR-96-0400

TO: $\quad$ P. F. Cloessner, 773-A

FROM: $\quad$ L. L. Tovo, 773-A (5-8378)

W. T. Boyce, 773-A (5-8178)

c: D. D. Walker, 773-A

S. D. Fink, 773-A

W. L. Tamosaitis, 773-A

A. L. Blancett, 773-A

C. J. Coleman, 773-A

M. S. Hay, 773-A

N. E. Bibler, 773-A

M. J. Barnes, 773-A

D. T. Hobbs, 773-A

R. E. Eibling, 704-T

C. L. Crawford, 773-41A

M. L. Hỳder, 773-A

D. J. McCabe, 773-43A

W. B. Van Pelt, 676-1T

A. W. Wiggins, 241-152H

P. L. Rutland, 241-152H

J. E. Marra, 704-56H 